\title{
Pelatihan Dasar-Dasar Pengoperasian GPS Garmin Bagi Mahasiswa Fakultas Pertanian Universitas Muhammadiyah Sorong
}

\author{
Anif Farida $^{1 *}$, Febrianti Rosalina ${ }^{2}$ \\ ${ }^{1}$ Program Studi Kehutanan, Universitas Muhammadiyah Sorong \\ ${ }^{2}$ Program Studi Agroteknologi, Universitas Muhammadiyah Sorong \\ *E-mail: aniffarida23@gmail.com
}

\begin{abstract}
ABSTRAK
Global Positioning System (GPS) merupakan teknologi yang sangat penting karena membantu untuk menentukan posisi koordinat di permukaan bumi. Pelatihan ini bertujuan untuk memberikan pengenalan tentang GPS Garmin, memperkenalkan feature-feature dan fungsi yang ada di dalam GPS Garmin, serta mengetahui respon mahasiswa terhadap pelatihan GPS. Metode dalam kegiatan pelatihan ini menggunakan metode ceramah untuk menyampaikan materi yang bersifat teori dengan menggunakan slide (powerpoint). Selanjutnyanmenggunakan metode demostrasi alat (materi yang bersifat praktek) dengan memperkenalkan alat secara langsung. Metode terakhir yang digunakan dalam pelatihan yaitu metode tanya jawab dan diskusi untuk mempertajam serta memperjelas tingkat pemahaman peserta terkait teori dan cara menggunakan GPS. Berdasarkan hasil pelatihan yang telah dilakukan maka dapat diperoleh informasi bahwa: 1) GPS merupakan sebuah sistem satelit navigasi yang berguna untuk mengetahui suatu posisi di permukaan bumi. 2) Komponen yang terdapat di dalam GPS terdiri dari unit antena sebagai penangkap sinyal satelit, unit display sebagai penampil informasi hasil pembacaan, unit receiver sebagai penerima sinyal satelit untuk memperkirakan posisi. 3) Prinsip kerja GPS adalah pengukuran jarak (range) antara receiver dengan satelit. Dimana pemancaran sinyal satelit yang diterima alat secara pasif paling tidak GPS harus memperoleh sinyal dari 3 satelit untuk dapat menentukan posisi dengan tepat. 4) Kelebihan GPS adalah dapat dioperasikan oleh setiap orang kapan saja dan dimana saja,karena pengoperasisannya yang cukup mudah, serta posisi koordinat geografis dapat diketahui dengan cepat. Namun, GPS juga memiliki kelemahan pada sinyalnya yang lemah karena pengaruh atmosfer serta sulit digunakan di dalam ruangan atau bila terhalang gedung tinggi. selain itu tingkat akurasinya di atas 1 meter apabila digunakan di daerah dengan tutupan kanopi yang lebat (sehingga menyebab pergeseran lokasi).
\end{abstract}

Kata kunci: Fitur; Garmin; Global Positioning System; Satelit

\begin{abstract}
Global Positioning System (GPS) is a very important technology because it helps to determine the position of coordinates on the surface of the earth. This training aims to provide an introduction to the Garmin GPS, introduce features and functions in the Garmin GPS, and find out students' responses to GPS training. The method in this training activity uses the lecture method to deliver material that is theoretical by using a slide (powerpoint). Furthermore, using the method of demonstration tools (material that is practical) by introducing the tool directly. The last method used in the training is the question and answer method and discussion to sharpen and clarify the level of understanding of the participants regarding the theory and how to use GPS. Based on the results of the training that has been done, information can be obtained that: 1) GPS is a navigation satellite system that is useful for knowing a position on the surface of the earth. 2) Components contained in the GPS consist of an antenna unit as a satellite signal catcher, a display unit as a reading information display result, a receiver unit as a satellite signal receiver to estimate position. 3) The working principle of GPS is the measurement of the distance between the receiver and the satellite. Where the satellite signal transmission is received passively at least the GPS must obtain signals from 3 satellites to be able to determine the exact position. 4) The advantage of GPS is that it can be operated by anyone anytime and anywhere, because its operation is quite easy, and the position of geographical coordinates can be known quickly. However, GPS also has a weakness in the signal that is weak because of the influence of the atmosphere and difficult to use indoors or when obstructed tall buildings. in addition the level of accuracy is above 1 meter when used in areas with dense canopy cover (thus causing a shift in location).
\end{abstract}

Keywords: Feature; Garmin; Global Positioning System; Satelite 


\section{PENDAHULUAN}

Global Positioning System (GPS) merupakan teknologi yang sangat penting karena membantu untuk menentukan posisi koordinat di permukaan bumi. Menurut Marjuki (2016) GPS (Global Positioning System) adalah sistem navigasi satelit yang menyediakan informasi lokasi dan waktu dalam berbagai kondisi cuaca, dimanapun di atas permukaan bumi, sepanjang masih menerima sinyal GPS yang di pancarkan dari satelit. Hal yang senada juga dikemukakan oleh Riyanto (2010), Global Positioning System (GPS) adalah suatu sistem radio navigasi penentuan posisi menggunakan satelit. GPS dapat memberikan posisi suatu objek di muka bumi dengan akurat dan cepat (koordinat tiga dimensi $\mathrm{x}, \mathrm{y}, \mathrm{z}$ ) dan memberikan informasi waktu serta kecepatan bergerak secara kontinyu di seluruh dunia.

Saat ini perkembangan GPS demikian pesat seiring dengan kebutuhan manusia akan teknologi. Hal ini menyebabkan semakin banyaknya tipe GPS yang beredar di kalangan umum. Pada dasarnya GPS dibedakan menjadi 3 tipe yaitu GPS Navigasi, GPS Geodetik, dan Geodetik Dual Frekuensi. GPS Navigasi adalah GPS handled yang mempunyai ketinggian 3-10 meter, biasanya bisa digengam. Selain berfungsi sebagai perangkat navigasi juga bisa digunakan untuk pemetaan. GPS Geodetik adalah GPS yang mempunyai ketelitian tinggi sampai milimeter. Alat ini terdiri dari base dan rover. Sedangkan Geodetik Dual Frekuensi dapat memberikan ketelitian posisi hingga mencapai millimeter. Tipe ini biasa digunakan untuk aplikasi precise positioning seperti pembangunan jaring titik kontrol, survey deformasi dan geodinamika. Harga receiver tipe ini cukup mahal, mencapai ratusan juta rupiah untuk setiap unitnya (Maulana, 2014).

Salah satu tipe GPS Navigasi yang cukup familiar adalah GPS Garmin. GPS ini cukup bagus digunakan untuk mengambil posisi koordinat di lapangan. Bahkan untuk kegiatan survey di perkebunan, pertanian maupun kehutanan jenis GPS Garmin paling banyak diaplikasikan untuk kegiatan pancang, penentuan jarak tanam dan sebagainya. Kisaran harga yang tidak teralu mahal membuat GPS ini banyak digunakan juga di bidang pendidikan sebagai bahan pembelajaran. Meskipun GPS Garmin mempunyai kelemahan tingkat akurasi di atas 1 meter, setidaknya dengan adanya GPS Garmin kita bisa menentukan posisi koordinat baik dengan sistem koordinat geografis (longitu latitude) maupun Universla Transverse Mercator (UTM).

Pelatihan pada dasarnya adalah suatu cara untuk meingkatkan tingkat pemahaman dan pengetahuan perserta terhadap suatu objek atau isu tertentu. Kamil (2003) menjabarkan pelatihan sebagai sebuah konsep program yang bertujuan untuk meningkatkan pengetahuan dan keterampilan seseorang (sasaran didik) agar berkembang pesat. Perkembangan model pelatihan seperti capacity building, empowering, training dan lain-lain dewasa ini tidak 
hanya terjadi pada dunia usaha, akan tetapi terjadi juga pada lembaga-lembaga profesional tertentu seiring dengan dengan kebutuhan belajar, proses belajar (proses edukatif), assessment, sasaran, dan tantangan lainnya. Mangkunegara (2012) mengemukakan pelatihan adalah suatu proses pendidikan jangka pendek dan singkat dengan mempergunakan prosedur yang sistematis dan teroganisir dengan baik dimana peserta pelatihan belajar pengetahuan dan ketrampilan teknis untuk mencapai suatu tujuan.

Kebutuhan data spasial di bidang pertanian menuntut pula kesiapan para tenaga terampil dan terdidik dalam pengelolaan data spasial. Data spasial yang akurat, cepat dan mutahkir menjadi satu kebutuhan yang penting apalagi di era digitalisasi seperti sekarang ini. Bahkan terkadang lulusan dari perguruan tinggi diharapkan memiliki keahlian khusus dalam bidang pengambilan data menggunakan GPS ketika mereka terjun dalam dunia kerja yang terkait. Ketidaksiapan para lulusan tersebut dengan teknologi GPS akan membuat mereka kesulitan nantinya jika berkecimpung dalam bidang survey lapangan.

Berdasarkan hasil observasi pendahuluan terhadap mahasiswa Fakultas Pertanian, sebagian besar dari mereka belum mengetahui dengan baik perihal teknologi GPS. Mereka mengetahui GPS hanya sebatas alat untuk menentukan posisi dan salah satu item yang ada dalam HP Android. Hal ini tentunya menjadi pertimbangan perlunya pelatihan terlebih di bidang pertanian kebutuhan data yang cepat dan akurat serta paling mutakhir sangat diperlukan. Di samping untuk mempersiapkan sumber daya manusia yang unggul di bidang geospasial sehingga dapat menjadi daya saing di era globalisasi. Mengingat aplikasi GPS sangat membantu dalam berbagai bidang, maka sebagai upaya dalam berkontribusi membangun sumber daya manusia yang unggul dan berkualitas, maka dibuatlah program pelatihan dasar-dasar pengoperasian GPS Garmin. Tujuan dari kegiatan ini adalah 1) untuk memberikan pengenalan tentang GPS Garmin; 2) Memperkenalkan feature-feature dan fungsi yang ada di dalam GPS Garmin; 3) Mengetahui respon mahasiswa terhadap pelatihan GPS. Dengan harapan sebelum mahasiswa nantinya melakukan pengambilan data di lapangan, mereka sudah mempunyai pengetahuan yang cukup mengenai teknologi GPS Garmin. Demikian pula pada saat mahasiswa sudah terjun ke dunia pekerjaan mreka sudah dibekali pengetahuan yang mumpuni khususnya GPS Garmin.

\section{METODE}

Kegiatan pelatihan ini dilaksanakan di Fakultas Pertanian Universitas Muhammadiyah Sorong dengan cara pemberian materi atau pengayaan dasar-dasar pengoperasian GPS. Teknik pengumpulan data dalam kegiatan ini meliputi data primer dan data sekunder. Data primer berupa hasil wawancara diperoleh melalui diskusi kepada mahasiswa Fakultas Pertanian terutama bagaimana opini mereka terhadap pelatihan yang dilaksanakan. Topik dalam wawancara tersebut sebagian besar berfokus pada teknis 
pelatihan dimana materi yang sudah disampaikan apakah dimengerti dan dipahami dengan baik oleh mahasiswa. Sedangkan data sekunder yang dikumpulkan antara lain studi pustaka tentang teknologi GPS (Global Positioning System). Data tersebut diperoleh dari jurnal, buku, skripsi maupun lieratur lain yang terkait dengan pemanfaatan teknologi GPS. Secara umum, metode yang digunakan selama pelatihan dapat dilihat pada Gambar 1 .

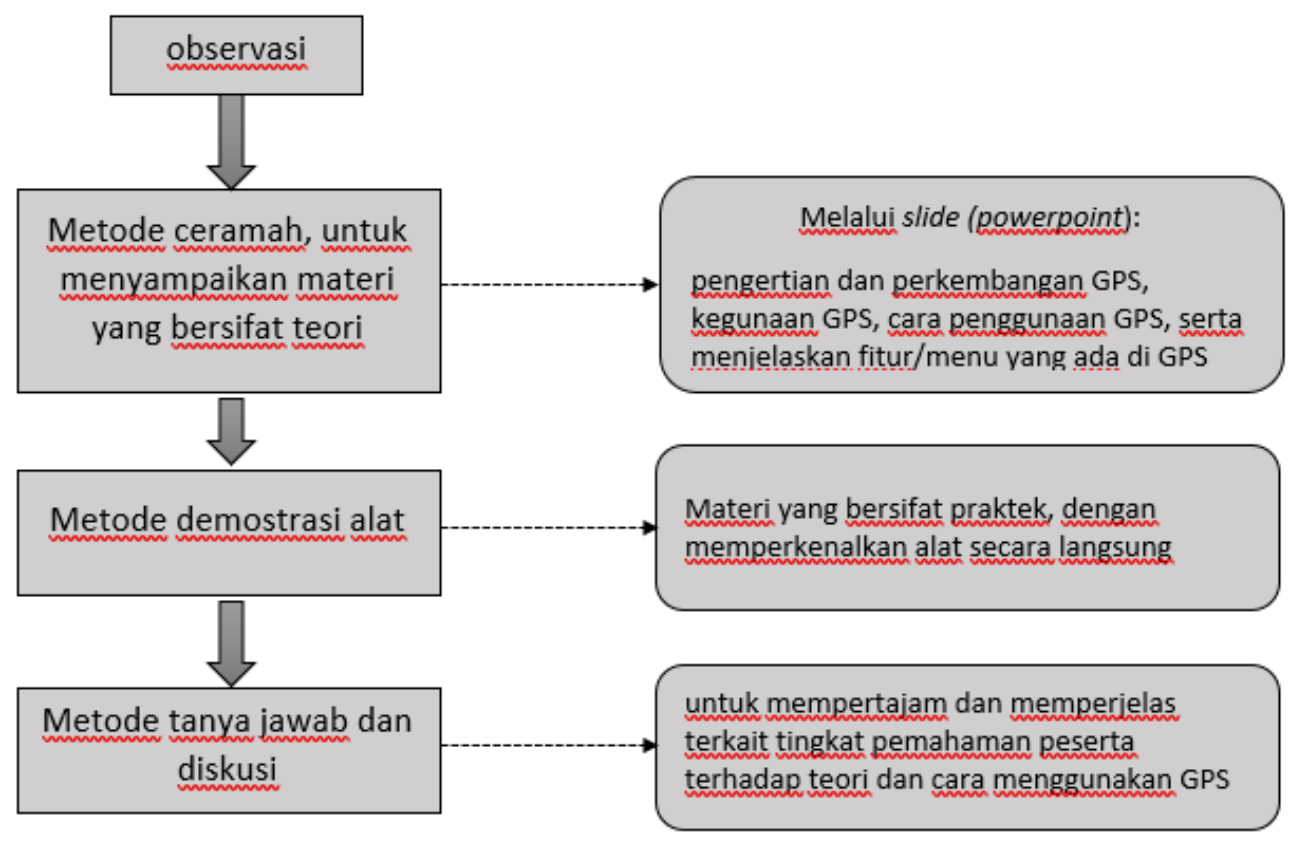

Gambar 1. Skema Pelaksanaan Pelatihan

\section{HASIL DAN PEMBAHASAN}

\section{Pengenalan GPS Garmin}

Garmin merupakan GPS tipe navigasi yang digunakan untuk aplikasi mapping (pemetaan) dan GIS (Geographic Information System). GPS Garmin merupakan GPS yang user friendly (mudah digunakan) dan memiliki kemampuan dalam penerimaan satelit yang baik terutama untuk pengumpulan data di bawah kanopi yang lebat. Kekurangan dari GPS Garmin adalah akurasi yang tidak bisa ditingkatkan dengan metode differential GPS sehingga akurasi yang dihasilkan tidak terlalu akurat. Adapun keakuratan dari GPS Garmin adalah $\pm 3-15 \mathrm{~m}$. 

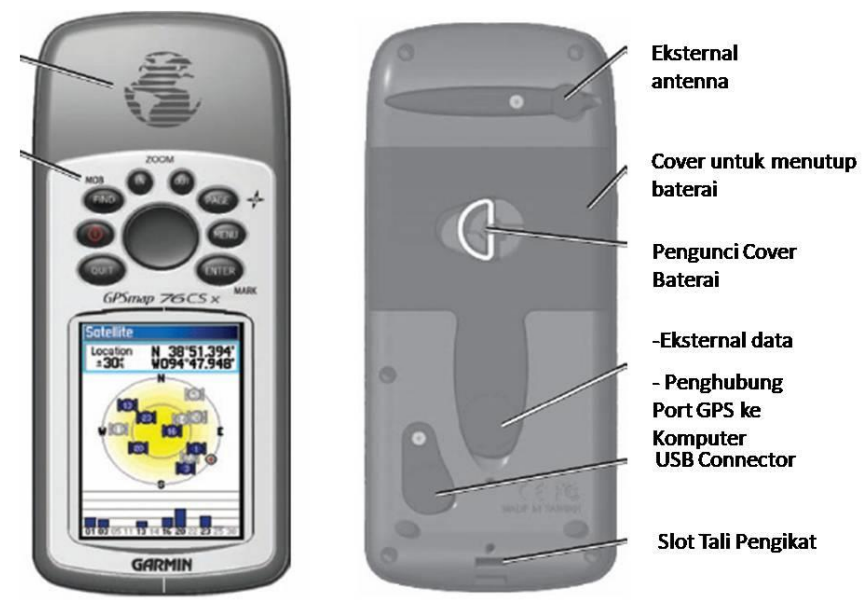

Gambar 2. Tampilan GPS

\section{Mempelajari Fungsi Tombol}

a. Power Key : Tekan dan tahan untuk menghidupkan atau mematikan unit. Tekan dan lepaskan untuk mengatur lampu backlight dan kecerahannya.

b. IN/OUT Key : Dari halaman peta, tekan untuk memperbesar atau memperkecil tampilan halaman peta. Dari halaman lain, tekan ke atas atau ke bawah untuk memilih daftar.

c. Find Key : Tekan dan lepaskan untuk melihat dan menemukan tempat yang ingin dicari, seperti : Waypoint, Restoran, Bank, Hotel, dll. Tekan dan tahan untuk feature MOB (Main Over Board).

d. Quit Key : Tekan dan lepaskan untuk membatalkan atau balik ke halaman sebelumnya.

e. Page Key : Tekan untuk menuju ke halaman berikutnya dan halaman utama

f. Menu Key : Tekan untuk melihat menu dari masig-masing halaman. Tekan dua kali untuk masuk ke halaman utama.

g. Enter Key : Tekan untuk memilih data yang tersorot atau untuk mengkonfirmasi pesan yang tampil di layar atau bisa digunakan untuk menyimpan Waypoint.

h. Rocker Key : Tekan ke atas, bawah, kiri, atau kanan untuk memilih karakter pada daftar, menyorot data, atau menggerakkan panah pada halaman peta.

\section{Feature-Feature dan Fungsinya dalam GPS Garmin}

\section{A. Satelit Page}

Satelite page menunjukkan status receiver (alat Garmin), posisi dengan kekuatan signal satelit dan posisi receiver berdiri saat itu juga. Saat digunakan alat perlu menangkap banyak signal satelite yakni di tempat terbuka dan cuaca cerah. 


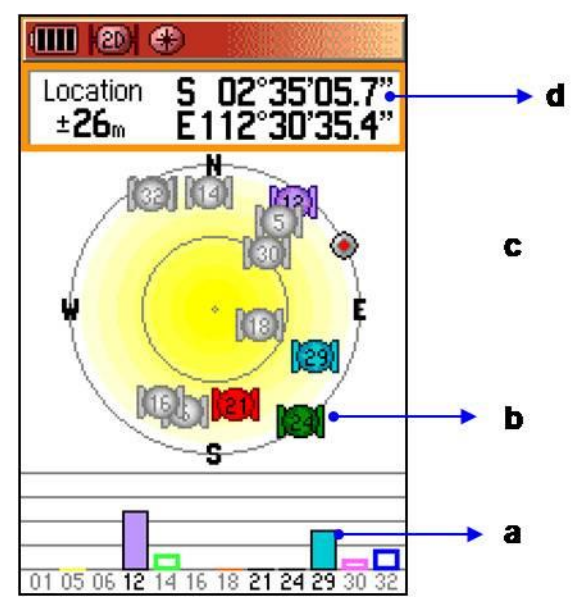

Gambar 3. Tampilan Satelit Page

Adapun item-item pendukungnya sebagai berikut :

a. Diagram Batang, menunjukkan kekuatan dari setiap satelite yang diterima.

b. Jumlah Satelit, digambarkan dengan bulat kecil dan berwarna-warni. Semakin banyak dan kuat jumlah satelit yang diterima, maka pengukuran semakin valid.

c. "Heading Bug", menunjukkan arah pergerakan GPS.

d. Koordinat, menunjukkan posisi tempat GPS.

Pertama menghidupkan Garmin kita akan mendapatkan feature satelit, dimana kita ditunjukkan berapa jumlah satelite yang diterima (semakin banyak jumlah satelit yang diterima semakin baik tingkat akurasinya). Layar GPS pertama kali akan menunjukkan 3 satelit (tergantung kondisi lapangan dan cuaca). Jumlah satelit bukan merupakan patokan, tetapi kita melihat angka accuracy yang ada di layar (untuk GPS Garmin $\pm 3-15 \mathrm{~m}$ ). Di samping layer satelit ada layer diagram batang, diagram ini menunjukkan tingkat kekuatan/ akurasi setiap satelit (pada Garmin GPS 76 SCX layer ini ada di bawah layer satelite).

\section{B. Trip Computer Page}

Feature ini membantu kita dengan data statistik untuk navigasi. Pada feature ini, item yang ditampilkan sebagai berikut :

a. Speed, menunjukkan kecepatan rata-rata kita bergerak.

b. Total Time, menunjukkan total waktu kita selama penggunaan GPS.

c. Dist To Dest, menunjukkan jarak kita dengan tempat yang ingin dituju.

d. Elevation, menunjukkan ketinggian suatu tempat.

e. Odometer, menunjukkan total perjalanan yang telah ditempuh.

f. Time of Day, menunjukkan jam/ waktu setempat. 


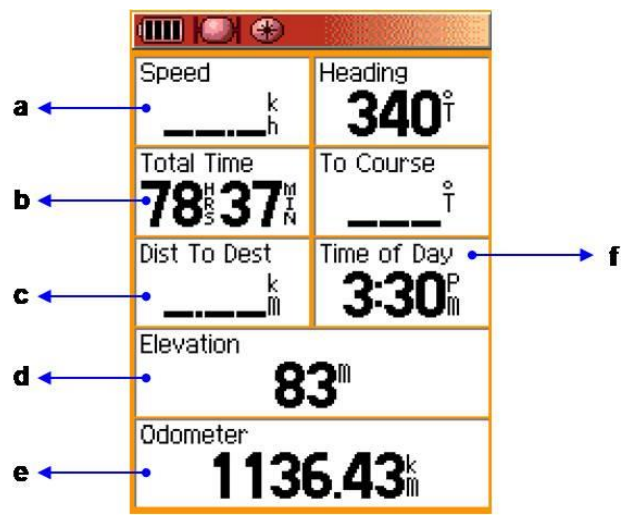

Gambar 4. Tampilan Trip Computer Page

\section{Map Page}

Pada feature peta ingin menampilkan peta dimana kita berada. Dalam feature ini, item-item yang mendukung sebagai berikut :

a. Lokasi Koordinat, menunjukkan lokasi point berada (titik kooordinatnya).

b. Zoom, proses zoom dapat dilakukan dengan menekan tombol In dan Out. Range untuk zoom adalah $0.2 \mathrm{mi}-200 \mathrm{ft}$.

c. Jarak Point, menunjukkan berapa jauh jarak suatu point dengan tempat yang ingin dicapai.

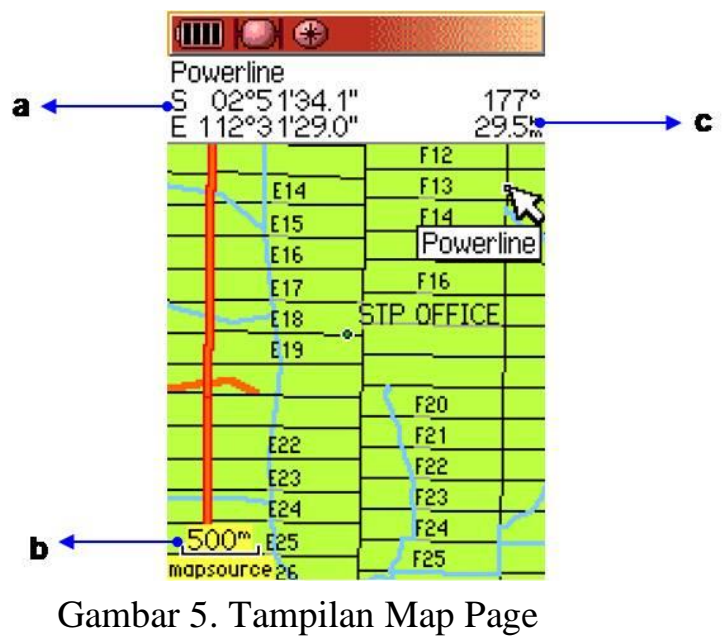

Hal-hal yang penting untuk diperhatikan dalam Map Page :

- Tanda ? menunjukkan data satelit belum menunjukkan posisi yang sebenarnya. Tunggu beberapa saat sampai tanda tersebut hilang dan berganti dengan tanda panah hitam 
- Tekan $\Delta$ tombol besar bagian tengah (ROCKER) akan muncul tanda panah putih untuk menggeser screen ke kanan-kiri atau atas-bawah.

- Gunakan tombol IN dan OUT untuk memperbesar-kecil map (Zooming).

- Tekan Menu untuk setting Map Page berisi Data Fields, Change Data Fileds, Guidance Text, Setup Map dan lain-lain.

\section{Compass Page}

Pada feature ini merupakan kompas digital yang berfungsi untuk menunjukkan arah dalam perjalanan. Item-itemnya sebagai berikut :

a. Ring Kompas, ring ini bekerja seperti kompas magnetic dan fungsinya untuk menunjukkan arah mata angin.

b. Pointer Penunjuk, dilambangkan dengan mata panah.

c. On/Off, penunjuk apakh kompas dalam kondisi aktif atau mati.

d. Speed, menunjukkan kecepatan rata-rata kita bergerak.

e. ETA At Dest, menunjukkan waktu/ jam.

f. Time to Next, waktu yang diperlukan untuk mencapai tujuan.

g. Dist To Next, jarak yang diperlukan untuk mencapai tujuan.

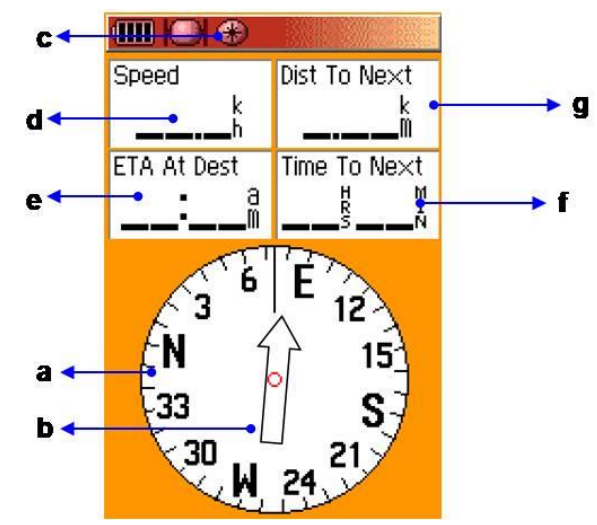

Gambar 6. Tampilan Compass Page

\section{E. Altimeter Page}

Pada feature ini menampilkan ukuran ketinggian suatu tempat, item yang ditampilkan sebagai berikut :

a. Elevation, menunjukkan ketinggian rata-rata suatu tempat.

b. Ketinggian Elevasi, menunjukkan ketinggian suatu tempat.

c. Profile Elevasi, menunjukkan kondisi elevasi suatu tempat.

d. Skala Pengukuran, menunjukkan skala dalam profile elevasi.

e. Max Elev, ketinggian maksimum. 


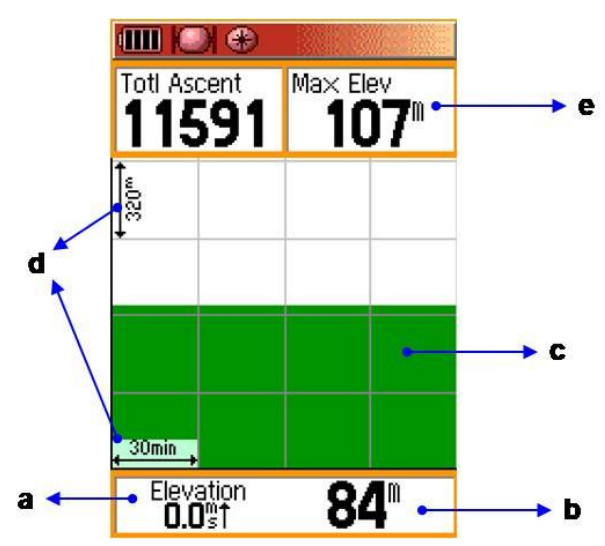

Gambar 7. Tampilan Altimeter Page

\section{F. Main Menu}

Main Menu termasuk ke dalam Page Interface atau dengan menekan tombol MENU 2x. Untuk menjalankan menu arahkan Rocker key ke menu yang tersedia kemudian tekan ENTER. Pada feature ini menampilkan menu untuk melakukan pengaturan pada beberapa layar yang ada pada GPS. Banyak feature-feature dalam GPS yang perlu diatur disesuaikan dengan kondisi dan lokasi suatu tempat. Pengaturan ini dapat juga dilakukan pada Tracks, Routes, Units dan lain-lain.

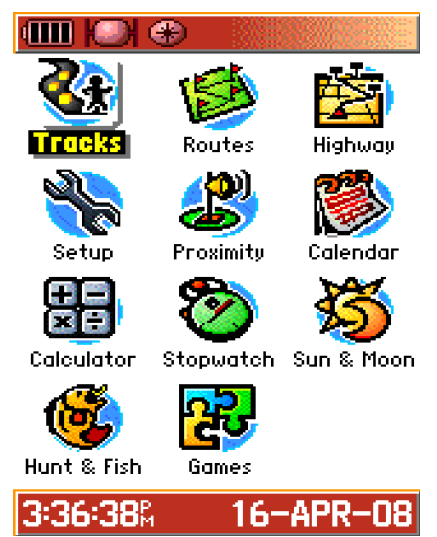

Gambar 8. Tampilan Main Menu

\section{SIMPULAN}

Berdasarkan hasil kegiatan pelatihan yang telah dilakukan, maka dapat disimpulkan bahwa:

a. GPS merupakan sebuah sistem satelit navigasi yang berguna untuk mengetahui suatu posisi di permukaan bumi.

b. Komponen yang terdapat di dalam GPS terdiri dari unit antena sebagai penangkap sinyal satelit, unit display sebagai penampil informasi hasil pembacaan, unit receiver sebagai penerima sinyal satelit untuk memperkirakan posisi 
c. Prinsip kerja GPS adalah pengukuran jarak (range) antara receiver dengan satelit. Dimana pemancaran sinyal satelit yang diterima alat secara pasif paling tidak GPS harus memperoleh sinyal dari 3 satelit untuk dapat menentukan posisi dengan tepat.

d. Kelebihan GPS adalah dapat dioperasikan oleh setiap orang kapan saja dan dimana saja,karena pengoperasisannya yang cukup mudah, serta posisi koordiant geografis dapat diketahui dengan cepat. Namun, GPS juga memiliki kelemahan pada sinyalnya yang lemah karena pengaruh atmosfer serta sulit digunakan di dalam ruangan atau bila terhalang gedung tinggi. selain itu tingkat akurasinya di atas 1 meter apabila digunakan di daerah dengan tutupan kanopi yang lebat (sehingga menyebab pergeseran lokasi).

\section{DAFTAR PUSTAKA}

Kamil, M. Model-Model Pelatihan. 2003. Universitas Pendidikan Indonesia. Bandung.

Mangkunegara, A.A. Anwar Prabu. 2014. Evaluasi Kinerja SDM. PT Refika Aditama. Bandung.

Marjuki, B. 2016. Survei Pemetaan Menggunakan GPS Dan GIS. Jakarta.

Maulana, I. 2014. Pengukuran GPS Geodetik dan Terrestrial Laser (TLS) untuk Pembangunan Rel Kereta Api Baru Di Menteng Jaya Jakarta. Universitas Pendidikan Indonesia. Bandung.

Riyanto. 2010 . Sistem Informasi Geografis Berbasis Mobile. Gava Media. Yogyakarta. 